\title{
ECLETICA
}

www.scielo.br/eq

Volume 31, número 4, 2006

\section{Otimização e validação de metodologia cromatográfica para determinação simultânea de composição monomérica em polímero biodegradável}

\author{
J. L. Souza, A. F. dos Santos, L. Polese, M. S. Crespi, C. A. Ribeiro \\ Instituto de Química - UNESP - 14801-970 - Araraquara - SP
}

Resumo: O biopolímero poli(3-hidroxibutirato) PHB, importante pelas suas propriedades de biodegradabilidade e biocompatibilidade, pode apresentar melhores características termoplásticas quando estruturalmente modificado com anidrido maleico (AM). Para avaliar a proporção de anidrido maleico presente nos filmes de PHB com a proporção no intervalo de 0 a $20 \%$ de AM para o PHB, foram otimizadas as condições experimentais e determinados os principais parâmetros de validação para a análise simultânea de derivados de PHB e AM, utilizando-se cromatografia em fase gasosa (GC). Os resultados demonstram que o procedimento analítico pode ser aplicado com confiabilidade.

Palavras-chave: poli(3-hidroxibutirato); anidrido maleico; validação de metodologia.

\section{Introdução}

O PHB poli(3-hidroxibutirato), polímero biossintetizado por microorganismos se acumula na célula microbiana em forma de grânulos como reserva de carbono e energia[1]. As propriedades termoplásticas do PHB são semelhantes às do polipropileno isotático com respeito à sua cristalinidade e temperatura de fusão. Considerase o PHB como um poliéster termoplástico biocompatível e biodegradável, por outro lado sendo quebradiço e termicamente instável seu uso em materiais tem sido restringido, pois apresenta baixas propriedades mecânicas.

O PHB tem sido melhorado com a introdução de monômeros de alcanoatos para produzir poliéster ou misturas poliméricas de PHB com outros polímeros[2,3]. Para alcançar condições ótimas no processo industrial e obter produtos com melhores propriedades avaliou-se a influencia de anidrido maleico como modificador de cadeia do PHB considerando os campos com potencial de aplicação[4].

A otimização e a validação de uma metodologia analítica eficiente para a determinação simultânea de PHB e anidrido maleico por cromatografia gasosa, são importantes para avaliar com precisão a composição de filmes com diferentes proporções de anidrido maleico e estudar possíveis alterações na composição dos mesmos.

\section{Material e Métodos}

\section{Reagentes, Padrões e Solventes}

PHB na forma de grânulos, proveniente da PHB Industrial (Serrana, SP), foi produzido industrialmente por rota biossintética a partir de sacarose invertida e foi submetido a modificação com anidrido maleico na presença de trietilamina. Como padrão foi utilizado o PHB proveniente da Sigma-Aldrich. 
Anidrido maleico 99\% (Merck), trietilamina 99\% (Vetec), Álcool iso-amílico 98,5\% (Vetec), Ácido benzóico 99,5\% (Vetec), Ácido clorídrico 37\% (Mallinckrodt) e acetona 99,5\% (Merck) foram empregados na análise.

\section{Equipamentos}

Cromatógrafo a gás modelo CP-3380 da Varian equipado com injetor modelo 1177 ("split-splitless"), coluna zbwax (30m x 0,53mm x 1?m) detector de ionização em chama (FID) e software para aquisição e processamento de dados Star Workstation da Varian.

Estufa Tecnal Modelo TE-394/2 com circulação e renovação de ar.

Banho de aquecimento Tecnal Modelo Te800.

Mesa agitadora Marconi modelo MA-141.

\section{Purificação do $P H B$}

Aproximadamente $120 \mathrm{~g}$ de PHB foi lavado com $300 \mathrm{~mL}$ de acetona, sob vácuo. O polímero foi transferido para placa de Petri e seco em estufa com circulação e renovação de ar à $40^{\circ} \mathrm{C}$ durante 18 horas.

\section{Preparação de filmes de PHB/AM}

Na Tabela 1 estão apresentadas as diferentes massas de PHB granulado que foram solubilizadas em $2 \mathrm{~mL}$ de clorofórmio em frascos de vidro de borosilicato com vedação de Teflon ${ }^{\circledR}$. Os frascos foram aquecidos durante 10 minutos em banho de areia $\left(100^{\circ} \mathrm{C}\right)$ e posteriormente foram mantidos a 90 rotações por minuto (RPM) durante 20 horas à temperatura ambiente.

Anidrido maleico foi dissolvido em $2 \mathrm{~mL}$ de clorofórmio e aquecido a $100^{\circ} \mathrm{C}$ durante 10 minutos. Após o resfriamento, a solução de anidrido maleico foi transferida para o frasco

Tabela 1. Proporções de PHB e AM nos filmes preparados

\begin{tabular}{ccc}
\hline FILME & MASSA DE PHB $(\mathrm{g})$ & MASSA DE AM $(\mathrm{g})$ \\
\hline $1(80 / 20)$ & 0,1670 & 0,0410 \\
$2(90 / 10)$ & 0,1708 & 0,0227 \\
$3(93 / 07)$ & 0,1858 & 0,0146 \\
$4(95 / 05)$ & 0,1908 & 0,0109 \\
$5(97 / 03)$ & 0,1961 & 0,0060 \\
$6(99 / 01)$ & 0,2000 & 0,0021 \\
\hline
\end{tabular}

contendo a solução de PHB, de modo a preparar vários filmes com diferentes proporções de anidrido (Tabela 1).

A reação de esterificação foi conduzida a $110^{\circ} \mathrm{C}$ durante 1 hora na presença de uma amina terciária como catalisador (trietilamina) com volume de $200 \mu \mathrm{L}$ de (concentração de $5 \%$ v/v).

Filmes de PHB puro, PHB/amina, anidrido puro e anidrido/amina foram preparados conforme procedimento descrito para a preparação dos filmes de PHB/AM.

Em seguida a solução foi transferida para placa de petri que foi mantida aberta em capela sem exaustão durante 24 horas para evaporação dos componentes voláteis e conseqüente formação do filme.

\section{Determinação do teor de PHB e anidrido maleico por GC-FID}

Uma solução reagente foi preparada adicionando $80 \mathrm{~mL}$ de álcool isoamílico, contendo $8 \%$ de ácido clorídrico concentrado e $0,12 \%(\mathrm{~m} / \mathrm{v})$ de ácido benzóico (padrão internoPI). Após homogeneização, a solução foi transferida para frasco âmbar que foi mantido sob refrigeração (entre 0 e $4^{\circ} \mathrm{C}$ ).

Em frascos $(8 \mathrm{~mL})$ foram pesados grânulos do padrão de PHB (Sigma-Aldrich), e adicionados $3 \mathrm{~mL}$ de solução reagente. Após aquecimento de $100^{\circ} \mathrm{C}$ em banho de areia durante 4 horas as amostras foram resfriadas rapidamente em banho de água durante 10 minutos. Após adição de $3 \mathrm{~mL}$ de água deionizada e agitação manual vigorosa, os frascos foram mantidos em repouso (1 hora) para separação das fases.

Alíquotas de $1,0 \mu \mathrm{L}$ foram diretamente injetadas no GC-FID para separação na coluna zbwax e detecção por FID. Utilizou-se o sistema de injeção (Injetor 1177) no modo splitless, portanto sem divisão de amostra, tendo em vista o limite de detecção do equipamento para a resposta do anidrido maleico.

Os ensaios de recuperação de $\mathrm{HB}$ e MI foram realizados em três diferentes níveis de concentração, sendo baixo, médio e alto, porém dentro do intervalo de concentração de trabalho do método.

As temperaturas do injetor e do detector foram mantidas em $230^{\circ} \mathrm{C}$ e $260^{\circ} \mathrm{C}$, respec- 
tivamente. A coluna foi aquecida de 90 a $220^{\circ} \mathrm{C}$ com razão de $8^{\circ} \mathrm{C} \mathrm{min}-1$ e isoterma em $220^{\circ} \mathrm{C}$ de 3 minutos. A sensibilidade do detector foi mantida no valor máximo (Range 11)

As amostras de filmes de PHB/AM foram submetidas ao mesmo tratamento de preparação dos padrões, utilizando-se massa de aproximadamente $0,018 \mathrm{~g}$, considerando o intervalo de linearidade da curva de resposta obtida com os padrões de PHB e AM para determinação simultânea dos ésteres isoamílicos. Alíquotas (1?L) da fase orgânica foram analisadas por GC-FID e a quantificação dos ésteres isoamílicos dos monômeros de PHB e maleato de isoamila (derivado de anidrido maleico) foi realizada a partir da curva de resposta por comparação com os padrões.

\section{Resultados e Discussão}

O teor de PHB e anidrido maleico podem ser determinados simultaneamente utilizando a metodologia cromatográfica apresentada.

Soluções com diferentes concentrações de padrão de $\mathrm{PHB}$, anidrido maleico e com a mesma concentração de ácido benzóico foram esterificadas com álcool isoamílico e analisadas por GC-FID. Após esterificação, alíquotas de $1 \mu \mathrm{L}$ da fase orgânica foram injetadas no GC-FID em triplicata no mesmo dia. Os volumes injetados correspondem à massa entre 1 e $18 \mathrm{mg}$ para o $\mathrm{PHB}$, entre 0,5 e $5 \mathrm{mg}$ para o anidrido maleico e a concentração de PI foi a mesma para todos os padrões.

Com a hidrólise em meio ácido e esterificação determina-se por GC-FID os ésteres correspondentes, que são maleato de isoamila (MI), 3-hidroxibutirato de isoamila (HB) e benzoato de isoamila (padrão interno - PI).

Os cromatogramas da análise em branco e da solução padrão de MI, HB e PI estão apresentados na Figura 1 e Figura 2, respectivamente.

O cromatograma da Figura 1, corresponde a análise em branco da solução reagente com apenas o pico do solvente no início da análise cromatográfica e em 11,109 minutos o pico referente ao PI.

Os picos em 8,850, 11,095 e 13,663 minutos no cromatograma da Figura 2 são

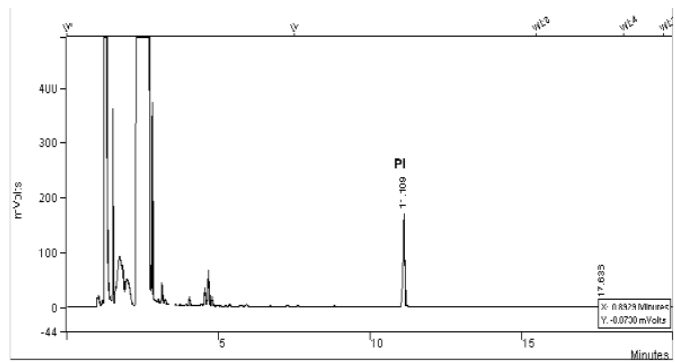

Figura 1. Cromatograma da análise em branco (solução reagente).

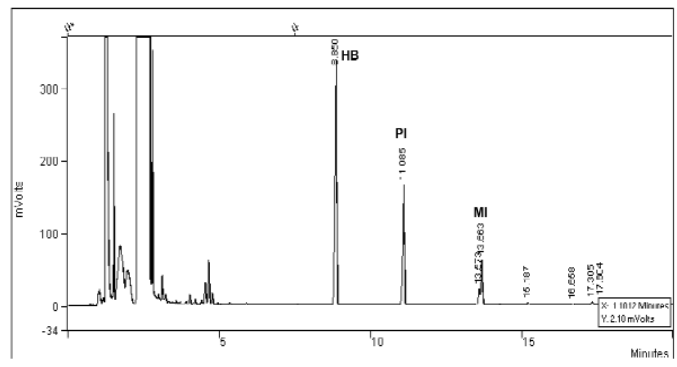

Figura 2. Cromatograma da solução padrão de HB, PI e MI.

referentes ao ésteres derivados do PHB, ácido benzóico e anidrido maleico, respectivamente. $\mathrm{O}$ tempo total de análise foi de 19 minutos.

Para determinação do teor de HB e MI nos filmes são construídas curvas de resposta do sinal analítico (relação de área de HB/PI ou MI/PI) contra massa do padrão de HB e MI.

$\mathrm{Na}$ Figura 3 estão apresentadas as curvas de resposta analítica (área média HB/PI) em função da massa de $\mathrm{HB}$, além do fator de resposta, (FR) dado pela relação de área média HB/PI sobre a massa de HB em função da massa de HB ilustrando o intervalo de linearidade dentro dos limites aceitos para validação do método [7]. Na Figura 4 estão apresentadas às curvas de respostas para o MI.

Os parâmetros do processo de validação do método para determinação do teor de HB e MI foram calculados de maneira semelhante àquela descrita no método para quantificação do teor de 3-hidroxibutirato de metila e 3-hidroxivalerato de metila [6]. 


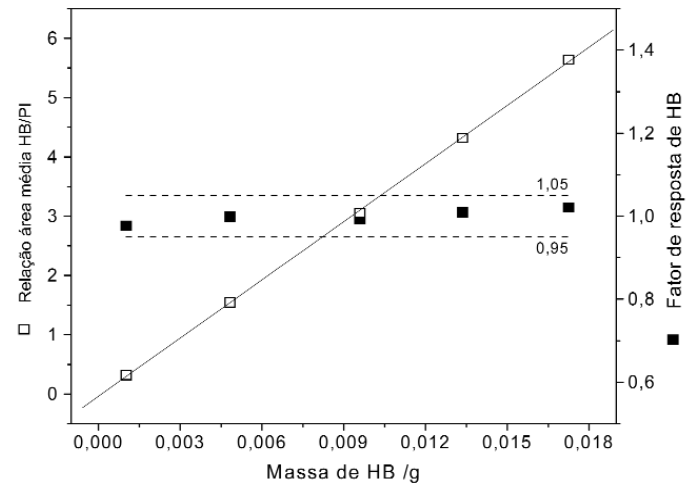

Figura 3. Reposta analítica (relação área HB/PI) e fator de resposta de $\mathrm{HB}$ submetidos à derivação.

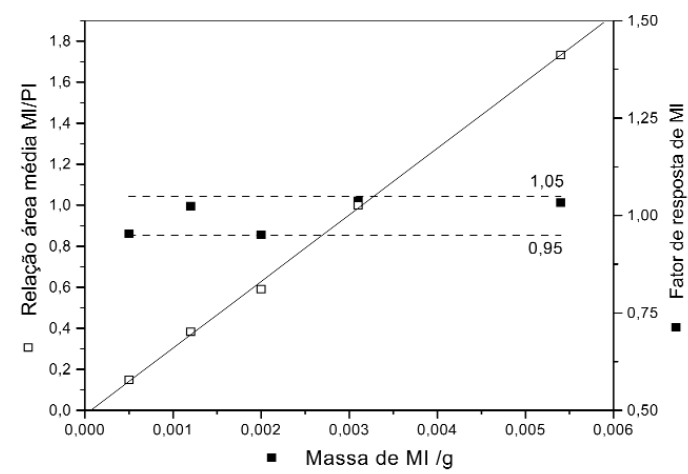

Figura 4. Reposta analítica (relação área MI/PI) e fator de resposta de MI submetidos à derivação.
Principais parâmetros de validação: sensibilidade do método, precisão dada pela repetibilidade das injeções, recuperação em três diferentes níveis de concentração e desvio padrão (DP) $(n=3)$, limite de detecção (LD) e limite de quantificação (LQ), no intervalo de massa dos padrões analisados para o HB e MI, estão descritos na Tabela 2. Os resultados obtidos no método proposto para determinação simultânea de HB e MI estão coerentes com os estudos de validação empregando hidrólise ácida e esterificação com metanol [6].

Os resultados de porcentagem de $\mathrm{HB}$ e de MI determinados por GC-FID nos filmes preparados estão descritos na Tabela 3.

A aplicação da metodologia apresentada possibilita quantificar os monômeros de PHB e de anidrido e obter informações adicionais sobre a atuação do catalisador (trietilamina) utilizado na reação de esterificação, quanto a possíveis reações anidrido/amina ou resíduos de amina presente nos filmes.

A soma dos valores de porcentagem de $\mathrm{HB}$ e MI indica que durante a reação de modificação de cadeia do PHB com anidrido maleico podem ter formado estruturas distintas dos padrões, devido à possíveis interações de $\mathrm{HB}$ e AM com a trietilamina levando a um aumento da afinidade pela fase aquosa, assim não foram identificadas nem quantificadas na análise por GC-FID.

A avaliação do perfil cromatográfico dos filmes de PHB puro em comparação com

Tabela 2. Parâmetros do processo de validação do método para determinação de HB e MI

\begin{tabular}{l|r|r|r}
\hline \multirow{2}{*}{ PARÂMETROS } & \multicolumn{2}{|c|}{ VALORES } & \multirow{2}{*}{ UNIDADES } \\
\cline { 2 - 3 } & $\mathrm{HB}$ & $\mathrm{MI}$ & \\
\hline Sensibilidade & 327 & 325 & Relação de área/g \\
Intervalo de trabalho & $0,0009-0,0188$ & $0,0005-0,0054$ & $\mathrm{~g}$ \\
Precisão (repetitividade) & 2,06 & 5,06 & $\%$ \\
& $0,0049 \mathrm{~g}=>105 \pm 5$ & $0,0007 \mathrm{~g}=>86 \pm 2$ & \\
Recuperação & $0,0142 \mathrm{~g}=>101 \pm 1$ & $0,0013 \mathrm{~g}=>92 \pm 1$ & $\mathrm{~g}$ \\
Média \pm DP & $0,0182 \mathrm{~g}=>105 \pm 1$ & $0,0030 \mathrm{~g}=>97 \pm 1$ & $\mathrm{~g}$ \\
LD do método & 0,0016 & 0,0002 & 0,0007 \\
LQ do método & 0,0048 & & \\
\hline
\end{tabular}


Tabela 3. Porcentagem de HB e MI determinadas por GC-FID

\begin{tabular}{lrr}
\hline AMOSTRA & $\% \mathrm{HB}$ & $\% \mathrm{MI}$ \\
\hline $1(80 / 20)$ & 70,1 & 14,7 \\
$2(90 / 10)$ & 80,0 & 10,6 \\
$3(93 / 07)$ & 96,5 & 7,7 \\
$4(95 / 05)$ & 99,0 & 5,8 \\
$5(97 / 03)$ & 103,5 & $\mathrm{ND}$ \\
$6(99 / 01)$ & 106,7 & $\mathrm{ND}$ \\
PHB/amina & 106,0 & - \\
PHB puro & 106,2 & - \\
Anidrido/amina & - & 27,8 \\
Anidrido & - & 91,0 \\
\hline
\end{tabular}

PHB/amina e dos cromatogramas das amostras de anidrido puro e anidrido/amina não indicou a presença de pico que pode ser referente à trietilamina.

Para as amostras dos filmes 1 e 2, respectivamente com as maiores proporções de anidrido nos filmes de PHB/AM com 80/20 e $90 / 10$, a soma das porcentagens indica uma recuperação menor de $\mathrm{PHB}$ e de anidrido maleico, pois os ésteres não identificados com suas respectivas estruturas podem ter permanecido na fase aquosa.

Para os filmes 3 e 4 de PHB/AM a soma dos valores de PHB e AM apresentam uma esterificação completa da massa de filme e os respectivos valores de porcentagem de PHB e MI estão de acordo com os determinados no processo de validação do método.

Nas amostras de filmes 5 e 6 não foram detectados picos de MI, pois os valores de massa de AM utilizados na preparação dos filmes estão abaixo do intervalo de concentração de trabalho do método, considerando os valores de recuperação no nível 1 para o MI (Tabela 3).

Os resultados apresentados na Tabela 3 para as amostras de PHB puro, PHB/amina e filme 6 indicam que, provavelmente não ocorre interação PHB-trietilamina e com uma pequena proporção ou ausência de AM nas amostras recuperou-se $\mathrm{HB}$ com teor levemente acima do DP obtido no nível mais elevado de recuperação de HB.

A porcentagem de anidrido $(27,8 \%)$ determinada na amostra de anidrido/amina indica que o anidrido maleico pode interagir com a trietilamina, cujo produto pode possuir maior afinidade com a fase aquosa e injetando a fase orgânica espera-se menor valor de porcentagem de anidrido maleico.

A principal vantagem da metodologia apresentada é a substituição de solvente no processo de preparação de amostras, uma vez que utilizava-se clorofórmio e metanol para a reação de esterificação dos monômeros de PHB (derivação) [5,6], substituído por álcool isoamílico, com toxicidade relativamente menor.

\section{Conclusões}

O método para determinação simultânea de 3-hidroxibutirato de isoamila e maleato de isoamila por cromatografia gasosa foi validado e os parâmetros determinados mostram a segurança analítica para avaliar amostras de filme de PHB modificado com anidrido maleico.

As principais vantagens do procedimento proposto são a análise simultânea dos derivados de PHB e anidrido maleico e a substituição de clorofórmio e metanol por álcool isoamílico.

\section{Agradecimentos}

Ao Conselho Nacional de Pesquisa e Desenvolvimento - $\mathrm{CNPq}$ pelo suporte financeiro e à $\mathrm{PHB}$ Industrial S/A pela concessão das amostras de PHB.

Recebido em: 19/09/2006. Aceito em: 07/12/2006. 
J. L. Souza, A. F. dos Santos, L. Polese, M. S. Crespi, C. A. Ribeiro. Optimization and validation of chromatographic method for simultaneous determination of monomeric composition in biodegradable polymer.

Abstract: The poly(3-hydroxybutyrate) (PHB) are an important biopolymer with biodegradable and biocompatible properties. When PHB is submitted to structural modification with maleic anhydride (MA) is possible to obtain PHB with superior thermoplastic characteristics. A gas chromatography (GC) method has been optimized and validated for simultaneous determination of monomeric proportions ( 0 to $20 \% \mathrm{w} / \mathrm{w}$ in MA) in PHB/MA films. The results demonstrated that the analytical procedure is a consistent chromatographic method to identification and quantification from PHB and MA isoamilic esters derivatives.

Keywords: poly(3-hydroxybutyrate); maleic anhydride; chromatographic method validation

\section{Referências}

[1] C. R. Squio, G. M. F. Aragão, Química Nova 27 (2004) 615.

[2] L. Sharma, J. N. Hay, Polymer 41 (2000) 5749.

[3] L. J. Chen, M. Wang, Biomaterials 23(2002) 2631.

[4] C. Chen, B. Fei, S. Peng, Y. Zhuang, L. Dong, Z. Feng,. European Polymer Journal 38 (2002) 1663.
[5] S. Jan, C. Roblot, G. Goethals, J. Courtois, B. Courtois, E. N. Saucedo, J. P. Seguin, J. N. Barbotin, Analytical Biochemistry 225 (1995) 258.

[6] A. F. SANTOS, Caracterização, modificação e estudo cinético não isotérmico de poli(3-hidroxibutirato). 2005. 148 f. Dissertação (Mestrado em Química)-Instituto de Química, Universidade Estadual Paulista, São Paulo, 2005.

[7] M. Ribani, C. B. G. Bottoli, C. H. Collins, I. C. S. F. Jardim, L. F. C. Melo, Química Nova 27 (2004) 771. 